\title{
Assessment of apically extruded debris and irrigant produced by different nickel-titanium instrument systems
}

\section{Ebru KÜÇÜKYILMAZ(a) \\ Selcuk SAVAS(a) \\ Gokhan SAYGILI (b) \\ Banu UYSAL(b)}

(a) Izmir Katip Celebi University, Faculty of Dentistry, Department of Pediatric Dentistry, Izmir, Turkey.

(b) Izmir Katip Celebi University, Faculty of Dentistry, Department of Endodontic, Izmir, Turkey.

Declaration of Interests: The authors certify that they have no commercial or associative interest that represents a conflict of interest in connection with the manuscript.

Corresponding Author:

Ebru Küçükyilmaz

E-mail: ebrukucukyilmaz@hotmail.com

DOI: 10.1590/1807-3107BOR-2015.vol29.0002

Submitted: May 25, 2014

Accepted for publication: Aug 13, 2014

Last revision: Sep 30, 2014

\begin{abstract}
The aim of this study was to evaluate the preparation time and the amounts of apically extruded debris and irrigant using different nickeltitanium instrumentation systems. Forty-five extracted single-rooted mandibular premolar teeth were selected and divided into three groups. The root canals were instrumented according to the manufacturers' instructions, using a reciprocating single-file system, a single-file rotary system and a multiple-file rotary system. Bidistilled water was used as the irrigant solution. The apically extruded debris and irrigant were collected into preweighed Eppendorf tubes. The amounts of extruded debris and irrigant were assessed with a precision micro-balance. The Eppendorf tubes were incubated at $37^{\circ} \mathrm{C}$ for 15 days. After the incubation period, they were weighed again to assess the debris extrusion. The time required to prepare the canals was also recorded. The results were statistically analyzed using MANOVA and Bonferroni's adjustment. Considering the apically extruded debris and irrigant, there were no statistically significant differences among the groups $(p>0.05)$. The Reciproc group produced the highest debris $(0.000632 \pm 0.000162$ gr $)$ and irrigant $(0.844587 \pm 0.437814 \mathrm{ml})$ extrusion values. While the least extruded debris was observed with OneShape $(0,000431 \pm 0,000171 \mathrm{gr})$, the least extruded irrigant was observed with ProTaper system $(0.564147 \pm 0.370596 \mathrm{ml})$. Instrumentation was faster using the Reciproc than the other two instruments $(70.27 \pm 13.38 \mathrm{~s})(p<0.05)$. All of the instrumentation systems used in this study produced apical debris and irrigant extrusion. The reciprocating single-file system tended to produce more debris and irrigant extrusion, compared with the rotary systems. Considering the preparation time, the single-file systems appeared to be advantageous due to their working time.
\end{abstract}

Keywords: Dental Instruments /Instrumentation; Root Canal Irrigants; Root Canal Preparation.

\section{Introduction}

Root canal preparation is an important step in endodontic treatment, and it plays a key role in treatment success. During chemo-mechanical preparation of root canals, necrotic debris, pulp remnants, microorganisms, dentin chips and irrigants can be extruded into the apical region. ${ }^{1,2}$ These substances can lead to inflammation, flare-ups or healing delays. ${ }^{3}$

Numerous studies have evaluated the extrusion of intracanal materials through the periapical region. A common finding has been that all instrumentation 
techniques produce apical extrusion to a certain extent. ${ }^{4,5,6,7}$ However, the amount of apical extrusion can vary according to the technique used. ${ }^{67,89}$ It is generally accepted that instrumentation techniques that incorporaterotational action generateless debris than push-pull instrumentation, and the crown-down technique has been associated with the least amount of debris extrusion, compared with techniques involving a linear filing motion. Thus, engine-driven rotary systems have tended to extrude less debris than hand techniques. ${ }^{59,10}$

Most nickel-titanium instruments using torquecontrol devices work with different instrumentation techniques, such as rotational or reciprocal action. There are different designs available, with some having variations in flute depth, different tapers, or cross-sections and others having radial lands. ${ }^{6,11}$ Single-file nickel-titanium Reciproc systems and OneShape systems, which can prepare the entire root canal with only one instrument, were recently introduced. The Reciproc files are composed of M-Wire nickel-titanium, which offers increased flexibility. The reciprocating movement of the instrument reduces the risk of cyclic fatigue. ${ }^{11,12}$ In contrast, OneShape files employ traditional continuous rotation. They have a triangle-shaped cutting edge and two additional cutting edges, in the apical and coronal parts, as well as a crosssection that progressively changes from 3 to 2 cutting edges between the apical and coronal parts. This design offers optimal cutting action. ${ }^{12}$

To the best of our knowledge, although there have been similar studies in the literature, no studies have compared the extrusion of both apical debris and irrigation solution by reciprocating and rotary single-file systems to the extrusion by other preparation systems. The aim of this study was to evaluate the preparation time and theamount of apically extruded debris and irrigant using two new single-file systems, OneShape and Reciproc, compared with the rotary full-sequence ProTaper (Dentsply Maillefer, Ballaigues, Switzerland) system.

\section{Methodology}

The present study was approved by the Research Ethics Committee of the Izmir Katip Celebi University, under report no. 2014/60. In this study, 45 freshly extracted human mandibular premolar teeth with mature apices and straight root canals $\left(<5^{\circ}\right.$ according to the Schneider method) were selected..$^{13}$ The teeth were cleaned of external debris and soft-tissue remnants and were stored in saline solution. All of the teeth were analyzed with cone beam computed tomography (CBCT) (Newtom 5G, Verona, Italy) to ensure that they had single canals, as well as to assess the canal curve. Only single-rooted teeth with a single and round-shaped canal and a single apical foramen were included in the study. Teeth with calcification and internal resorption were excluded.

Forty-five teeth were classified into three groups:

1. Group 1: ProTaper instruments (Dentsply Maillefer, Ballaigues, Switzerland) were used according to the manufacturer's instructions as follows: S1, S2, F1 (20.07), and F2 (25.08) ( $\mathrm{n}=15)$;

2. Group 2: A R25 Reciproc file (VDW, Munich, Germany), size 25 at the tip and having a taper of 0.08 over the first $3 \mathrm{~mm}$, was used according to the manufacturer's instructions with reciprocal action $(\mathrm{n}=15)$;

3. Group 3: A OneShape file (Micro-Mega, Cedex, Besançon, France), size 25 at the tip and having a taper of 0.06 , was used according to the manufacturer's instructions with rotational motion $(n=15)$.

To standardize the working length of the specimens, all of the teeth were shortened to $15 \mathrm{~mm}$ by a highspeed hand piece burr. The working length of each tooth was determined by inserting a size $15 \mathrm{~K}$-file (Dentsply Maillefer, Ballaigues, Switzerland) into the canal until the tip of the file was minimally visible at the apical foramen. The working length was then set as $1 \mathrm{~mm}$ less than that of the canal length.

In this study, an experimental model was used, as described by Myers and Montgomery. ${ }^{14}$ Before starting the experiment, the initial weights of empty Eppendorf tubes (the stoppers of the tubes were not separated) were measured with $10^{-6} \mathrm{~g}$ precision electronic balance (Sartorius Cubis, Gottingen, Germany). One hundred sequential weights were obtained for each tube, using the Sarto Connect Version computer program, version 3.5 (Sartorius Cubis, Gottingen, Germany), which was specially designed to record one measurement per second. The mean value was calculated for each tube and was recorded as the precise weight. A hole was created in the middle of the removable stoppers that were used to fix the teeth, and each tooth was then inserted into the hole. The teeth were fixed with self-curing acrylic resin to create a 
hermetic seal. A 25-G needle was placed alongside the stopper to balance the air pressure inside and outside the tubes. After polymerization of the acrylic resin, to avoid any leakage, a second sealing was applied. The Eppendorf tubes were fitted into the glass vials used to hold the tubes during the instrumentation, to ensure that there was no contact with the tubes.

To avoid variation and to eliminate biases, the cleaning, shaping, and irrigation of all of the samples were completed by the same trained operator. Bidistilled water was used as the irrigant solution. In each sample, a total of $4 \mathrm{~mL}$ of bidistilled water was used as the irrigation solution between the files (Group 1) and between the pecking sequences (Groups 2 and 3). A 25-G irrigation needle was placed in the canal without resistance but not deeper than the predetermined working length minus $1 \mathrm{~mm}$.

After the instrumentation was complete, the stopper, needle, and tooth were separated from the tubes. The debris adhering to the root surface were collected by washing the root with $1 \mathrm{~mL}$ of bidistilled water in the tube. Each Eppendorf tube was weighed to determine the amount of debris and irrigant extruded to the periapical area. The tubes were then stored in an incubator at $37^{\circ} \mathrm{C}$ for 15 days to evaporate the moisture before weighing the dry debris. The weight was calculated by a second examiner, who was blinded to the group assignment. The Eppendorf tubes were weighed using the same analytical balance to obtain the final weight of the tubes, including the extruded debris. One hundred consecutive weights were obtained for each tube. The weight of the empty tube was subtracted from the weight of the tube containing debris, and the dry weight of the extruded debris was calculated for each tube.

The total preparation time, including total active instrumentation, instrument changes within the sequence, cleaning of the flutes of the instruments and irrigation, was recorded.

\section{Statistical Analysis}

Before beginning the study, a power analysis was performed with $G^{*}$ Power software, version 3.0.10 (Franz Faul-Christian Albrechts Universität, Kiel, Germany), to estimate the sample size. A power analysis was performed, based on the effects obtained from a prior pilot study with 5 specimens in each group. The analysis indicated that a total of 45 specimens could achieve $88.6 \%$ statistical power at an $\alpha=0.05$ significance level.

The amounts of extruded irrigant and debris and the preparation times were analyzed using the SPSS computer program, version 20.0 (IBM SPSS, Chicago, USA). The dependent variable across groups was examined in terms of assuming the existence of normality by performing the ShapiroWilk test and Levene's test for constant homogeneous variances. The test indicated that the variables across groups completely met the underlying assumption of parametric tests. Accordingly, the data were analyzed statistically using MANOVA and post-hoc Bonferroni adjustment at a significance level of $p<0.05$.

\section{Results}

For apical extrusion of debris and irrigant, although no statistically significant differences were obtained between the groups ( $p>0.05)$, Reciproc extruded more debris and irrigant compared with the other two instruments. While the least extruded debris was observed with OneShape, the east extruded irrigant was observed with ProTaper system. The mean values and standard deviations for all of the groups are presented in Table 1 .

Considering the preparation time, while there was no significant difference between the Reciproc and the OneShape groups $(p>0.05)$, there were statistically significant differences between the other groups $(p<0.05)$. The minimum preparation time was recorded with the Reciproc files. The mean values and standard deviations for all of the groups are presented in Table 2.

\section{Discussion}

Over the years, apical extrusion of intracanal materials has been investigated in many studies because of its clinical relevance. ${ }^{4,5,6,715,16}$ Apical extrusion of intracanal materials can delay periapical healing and cause inflammation and postoperative pain. ${ }^{3}$ Therefore, the main objective of this study was to evaluate the apical extrusion of debris and irrigant as a result of root canal preparation by different instrumentation systems. 
Table 1. Amount of Apically Extruded Debris (gram) and Irrigant (milliliter) after Use of the Different Instruments.

\begin{tabular}{lcccccc}
\hline & \multicolumn{3}{c}{ Extruded Debris } & & & \multicolumn{2}{c}{ Extruded Irrigant } \\
\cline { 2 - 7 } & Mean (SD) & Minimum & Maximum & Mean (SD) & Minimum & Maximum \\
\hline ProTaper & $0.000605^{a}$ & 0.000223 & 0.001372 & $0.564147^{a}$ & 0.206450 & 1.186482 \\
& $(0.000378)$ & & & $(0.370596)$ & & 1.587213 \\
Reciproc & $0.000632^{a}$ & 0.000457 & 0.000998 & $0.844587^{a}$ & 0.337517 & \\
& $(0.000162)$ & & & $(0.437814)$ & & 1.182645 \\
OneShape & $0.000431^{a}$ & 0.000144 & 0.000760 & $0.632451^{a}$ & 0.205335 & \\
& $(0.000171)$ & & & $(0.346483)$ & & \\
\hline
\end{tabular}

SD: Standard deviation

The letters indicate significantly different groups $(p<0.05)$.

Table 2. Preparation Time with the Different Instruments (second).

\begin{tabular}{lccc}
\hline Preparation Time & Mean \pm SD & Minimum & Maximum \\
\hline ProTaper & $135.40^{\mathrm{a}} \pm 31.91$ & 96 & 195 \\
Reciproc & $70.27^{\mathrm{b}} \pm 13.38$ & 53 & 93 \\
OneShape & $83.53^{\mathrm{b}} \pm 21.18$ & 45 & 123 \\
\hline
\end{tabular}

The letters indicate significantly different groups $(p<0.05)$.

The present study revealed that all of the instrumentation systems caused apical extrusion of debris and irrigants. The results were consistent with previous studies, which demonstrated that no method could completely prevent debris extrusion. ${ }^{14,16,17,18}$ Also, the results of the present study showed no significant differences in the amounts of debris and irrigant extruded between the single-file systems and the full-sequence rotary system. However, the reciprocating single-file system extruded more debris than the rotary instrument. This observation was in agreement with previous findings that rotary systems were associated with less debris extrusion than reciprocating systems. ${ }^{11,18}$ The obtained differences between the instruments might have been caused by the preparation technique, the different tapers and the cross-sectional design of the instruments. While Reciproc has an S-shaped, cross-sectional design with sharp cutting edges, ${ }_{11}^{11}$ OneShape is characterized by a changing triangular cross-section, ${ }^{12}$ and ProTaper is characterized by a triangular or modified triangular cross-section. ${ }^{16,19}$ It can be speculated that the larger taper of Reciproc at the tip compared with the other instruments and the reciprocal working motion might explain the greater amount of debris extrusion caused by this system. However, based on the available literature, it was not possible to determine whether it was the reciprocal motion that was responsible for the increased risk of debris extrusion. Further studies using standardized apical tapers are required to answer this question.

While the ProTaper system requires four instruments to prepare the root canal to a size of 25, the Reciproc and OneShape systems can complete root preparation with only one instrument. Thus, the single-file systems were faster than the multiplefile system, and the difference was statistically significant. This finding was consistent with previous studies in which the use of single-file systems reduced the working time, compared to using a multi-file rotary system. ${ }^{17,20}$

In previous studies, different techniques were used to measure the apically extruded debris and irrigant. ${ }^{14,21,22}$ In the current study, the generally accepted method of Myers and Montgomery, ${ }_{1}^{14}$ which is more standardized and repeatable than other methods, ${ }^{11,12}$ was used to collect the intracanal materials.

Many factors can affect the amount of extruded intracanal material. These factors include the instrumentation method, the instrument type and size, the size and length of the canal, the preparation endpoint, the apical stop preparation used, and the type and the amount of irrigant used..$^{4,6,11,23}$ In the present study, to minimize the effects of the aforementioned factors, standard conditions (other than the instrumentation system used) were created for all of the groups. The teeth were imaged using CBCT to ensure that they had single canals and orifices, and only single-rooted teeth with straight canals were used in this study to eliminate any possible variables. Before the instrumentation procedure, all of the teeth were decoronated to eliminate any possible 
variables associated with the working length of each tooth that might manifest as differences in debris extrusion. The working length for all of the specimens was $1 \mathrm{~mm}$ shorter than the root length. Studies have shown that significantly more debris extrusion occurs when the instrumentation is performed at the canal length than when the instrumentation is performed at $1 \mathrm{~mm}$ short of the canal length. ${ }^{14,24}$

In the current study, the type and quantity of the irrigants used were the same. Bidistilled water was used as an irrigation solution to avoid any possible weight increase due to crystallization of sodium hypochlorite. ${ }^{11,25}$ The amount of irrigation solution was kept constant in all of the groups, to decrease variables during the irrigation process.

There have been a number of studies in the literature on the amount of apically extruded dry debris. ${ }^{8,9,10,11,14,15,16,17}$ During chemo-mechanical preparation of root canals, irrigation solutions, as well as intracanal debris, can be accidentally extruded into the periapical area. These two components were responsible for post-operative flare-ups. ${ }^{26}$

\section{References}

1. Siqueira Junior JF, Rocas IN, Paiva SS, Guimaraes-Pinto T, Magalhaes KM, Lima KC. Bacteriologic investigation of the effects of sodium hypochlorite and chlorhexidine during the endodontic treatment of teeth with apical periodontitis. Oral Surg Oral Med Oral Pathol Oral Radiol Endod. 2007 Jul;104(1):122-30.

2. Seltzer S, Naidorf IJ. Flare-ups in Endodontics I. Etiological factors. J Endod. 1985 Nov;11(11):472-8.

3. Siqueira Junior JF. Microbial causes of endodontic flare-ups. Int Endod J. 2003 Jul;36(7):453-63.

4. Reddy SA, Hicks ML. Apical extrusion of debris using two hand and two rotary instrumentation techniques. J Endod. 1998 Mar;24(3):180-3.

5. Ferraz CC, Gomes NV, Gomes BP, Zaia AA, Teixeira FB, Souza-Filho FJ. Apical extrusion of debris and irrigants using two hand and three engine-driven instrumentation techniques. Int Endod J. 2001 Jul;34(5):354-8.

6. Albrecht LJ, Baumgartner JC, Marshall JG. Evaluation of apical debris removal using various sizes and tapers of ProFile GT files. J Endod. 2004 Jun;30(6):425-8.

7. Adl A, Sahebi S, Moazami F, Niknam M. Comparison of apical debris extrusion using a conventional and two rotary techniques. Iran Endod J. 2009 Fall;4(4):135-8.
Therefore, the present study focused on the extrusion of intracanal irrigants, in addition to solid debris.

It must be emphasized that the results of this study cannot be directly extrapolated to the clinical situation. Under clinical conditions, periapical tissues and bone serve as natural barriers against the apical extrusion of debris and irrigants. ${ }^{27}$ The present study was a laboratory investigation, and different results might be achieved with in vivo studies or in a clinical situation.

\section{Conclusion}

All of the instrumentation systems used in the present study produced apical extrusion of intracanal debris and irrigation solution.

Considering the preparation time, the single-file systems used in the study appeared to be advantageous due to their working time.

Considering the amounts of apically extruded debris and irrigant, the single file rotary instrumentation system, with the relatively small amounts of apically extruded debris and irrigant and short preparation time, might be preferable and should be investigated in clinical use.

8. Al-Omari MA, Dummer PM. Canal blockage and debris extrusion with eight preparation techniques. J Endod. 1995 Mar;21(3):154-8.

9. Azar NG, Ebrahimi G. Apically-extruded debris using the ProTaper system. Aust Endod J. 2005 Apr;31(1):21-3.

10. Bidar M, Rastegar AF, Ghaziani P, Namazikhah MS. Evaluation of apically extruded debris in conventional and rotary instrumentation techniques. J Calif Dent Assoc. 2004 Sep;32(9):665-71.

11. Bürklein S, Benten S, Schäfer E. Quantitative evaluation of apically extruded debris with different single-file systems: Reciproc, F360, and OneShape versus Mtwo. Int Endod J. 2014 May;47(5):405-9. DOI: 10.1111/iej.12161. Epub 2013 Jul 26.

12. Liu R, Hou BX, Wesselink PR, Wu MK, Shemesh H. The incidence of root microcracks caused by 3 different single-file systems versus the ProTaper system. J Endod. 2013 Aug;39(8):1054-6.

13. Schneider SW. A comparison of canal preparations in straight and curved root canals. Oral Surg Oral Med Oral Pathol. 1971 Aug;32(2):271-5.

14. Myers GL, Montgomery S. A comparison of weights of debris extruded apically by conventional filling and Canal Master techniques. J Endod. 1991 Jun;17(6):275-9. 
15. Elmsallati EA, Wadachi R, Suda H. Extrusion of debris after use of rotary nickel-titanium files with different pitch: A pilot study. Aust Endod J. 2009 Aug;35(2):65-9

16. Beeson TJ, Hartwell GR, Thornton JD, Gunsolley JC, Comparison of debris extruded apically in straight canals: conventional filling versus Profile 04 Taper series 29. J Endod. 1998 Jan;24(1):18-22.

17. Tanalp J, Kaptan F, Sert S, Kayahan B, Bayirli G. Quantitative evaluation of the amount of apically extruded debris using 3 different rotary instrumentation systems. Oral Surg Oral Med Oral Pathol Oral Radiol Endod. 2006 Feb;101(2):250-7

18. Altundasar E, Nagas E, Uyanik O, Serper A. Debris and irrigant extrusion potential of 2 rotary systems and irrigation needles. Oral Surg Oral Med Oral Pathol Oral Radiol Endod. 2011 Oct;112(4):e31-5.

19. Koçak S, Koçak MM, Sağlam BC, Türker SA, Sağsen B, Er Ö. Apical extrusion of debris using self-adjusting file, reciprocating single file and 2 rotary instrumentation systems. J Endod. 2013 Oct;39(10):1278-80.

20. Bürklein S, Hinschitza K, Dammaschke T, Schäfer E. Shaping ability and cleaning effectiveness of two single file systems in severely curved root canals of extracted teeth: Reciproc and Waveone versus Mtwo and ProTaper. Int Endod J. 2012 May;45(5):449-61.
21. Fairbourn DR, McWalter GM, Montgomery S. The effect of four preparation techniques on the amount of apically extruded debris. J Endod. 1987 Mar;13(3):102-8

22. McKendry DJ. Comparison of balanced forces, endosonic and step-back filing instrumentation techniques: quantification of extruded apical debris. J Endod. 1990 Jan;16(1):24-7.

23. Tinaz AC, Alacam T, Uzun O, Maden M, Kayaoglu G. The effect of disruption of apical constriction on periapical extrusion. J Endod. 2005 Jul;31(7):533-5.

24. Logani A, Shah N. Apically extruded debris with three contemporary NiTi instrumentation systems: an ex-vivo comparative study. Indian J Dent Res. 2008 Jul-Sep;19(3):182-185.

25. Bürklein S, Schäfer E. Apically extruded debris with reciprocating single-file and full-sequence rotary instrumentation systems. J Endod. 2012 Jun;38(6):850-2.

26. Nair PN. On the causes of persistent apical periodontitis: a review. Int Endod J. 2006 Apr;39(4):249-81.

27. Seltzer S, Soltanoff W, Sinai I, Goldenberg A, Bender IB. Biologic aspects of endodontics. 3. Periapical tissue reactions to root canal instrumentation. Oral Surg Oral Med Oral Pathol. 1968 Nov;26(5):534-46. 